\title{
FITOREGULADORES E GERMINAÇÃO DE SEMENTES DE MARACUJÁ DOCE EM CONDIÇÕES DE LABORATÓRIO
}

\section{PHYTOREGULATORS AND GERMINATION OF SWEET PASSION FRUIT SEEDS UNDER LABORATORY CONDITIONS}

\author{
ZUCARELI, C. ${ }^{1}$ \\ CASTRO, M.M. ${ }^{1}$ \\ OLIVEIRA, H.R. ${ }^{1}$ \\ BRANCALIÃO, S.R. ${ }^{1}$ \\ RODRIGUES, J.D. ${ }^{2}$ \\ ONO, E.O. ${ }^{3}$ \\ BOARO, C.S.F. ${ }^{3}$
}

\section{RESUMO}

\begin{abstract}
O experimento conduzido no Laboratório de Análise de Sementes do Departamento de Produção Vegetal - Setor Agricultura da Faculdade de Ciências Agronômicas do campus de Botucatu - UNESP, teve como objetivo avaliar a influência de fitorreguladores na germinação de sementes de Passiflora alata Curtis. Foram avaliados 14 tratamentos sob o delineamento experimental inteiramente casualizado com 4 repetições de 50 sementes cada. Os tratamentos constaram da aplicação dos fitorreguladores $\mathrm{GA}_{3}$, fenilmetiltetrahidro-piranil-aminopurina e ethephon nas concentrações de 75 e $150 \mathrm{mg}^{-\mathrm{L}^{-1}}$, isolados e combinados com as mesmas dosagens, das sementes embebidas somente em água destilada e das sementes sem qualquer tratamento (testemunha). As avaliações de emissão de radícula, porcentagem de plântulas normais e porcentagem de sementes duras foram avaliadas pelo teste de germinação sob temperatura constante de $25^{\circ} \mathrm{C}$, por 35 dias e temperatura de $20-30^{\circ} \mathrm{C}$, por mais 35 dias. Os fitorreguladores $\mathrm{GA}_{3}, \mathrm{~N}$-fenilmetil-9Tetra-Hidro-2H-2 piranil 9H-6 amino purina e ethephon, isolados ou em misturas, nas dosagens de 75 e $150 \mathrm{mg} \cdot \mathrm{L}^{-1}$ não favoreceram o processo germinativo de sementes de $P$. alata.
\end{abstract}

Palavras-chave: maracujá doce; Passiflora alata; reguladores vegetais; germinação.

\begin{abstract}
The experiment was carried out in Seed Analyze Laboratory of Department of Crop Science of São Paulo State University (UNESP) - Botucatu, Brasil. The objective of the experiment was to study the influence of phytoregulators on the germination of Passiflora alata Curtis seeds. Completely randomized blocks, with four replications, 14 treatments of 50 seeds per plot was the experimental design used in the assay. The treatments was composed by applications of GA3, phenylmethil-tetrahydro-pyranil-aminopurine, and ethephon phytoregulators on dosages of 75 and $150 \mathrm{mg} \mathrm{L}^{-1}$ and in combinations of couples of thoses. In the treatments were used two controls, being one with seeds only soaked in distilled water and, the other seeds that did not receive any treatment. The evaluations of initial root emission, percentage of normal seedling, and percentage of hard seeds were avaluated by germination test under $25^{\circ} \mathrm{C}$ temperature, during 35 days and after the seeds were remained more 35 days under $20-30^{\circ} \mathrm{C}$ temperature. GA3, N-phenylmethyl-9tetra-hydro-2 $\mathrm{H}-2$ pyranil $9 \mathrm{H}-6$ aminopurine, and ethephon phytoregulators, on the 75 and $150 \mathrm{mg} \mathrm{L}^{-1}$ dosages did not favor the process of P.alata seed germinations.
\end{abstract}

Key-words: sweet passion fruit; Passiflora alata; vegetable regulators; germination.

\footnotetext{
1Eng. Agr., Pós graduando do Programa de Pós Graduação em Agricultura, UNESP/FCA, Botucatu- SP. C. Postal 237, CEP 18603-970; ${ }^{2}$ Professor Titular, Departamento de Botânica, Instituto de Biociências, UNESP, Botucatu-SP. C. Postal 510, CEP 18618-000; ${ }^{3}$ Professor Assistente Dra., Departamento de Botânica, Instituto de Biociências, UNESP, Botucatu-SP.
} 


\section{INTRODUÇÃO}

O maracujá é uma planta típica de regiões tropicais e subtropicais, encontrando no Brasil excelentes condições de cultivo, adaptando-se à regiões de clima seco, desde que irrigada. Das 300 espécies pertencentes ao gênero Passiflora (11), mais de 150 são originárias do Brasil (10). O Passiflora alata Dryander é relatado como originário da região centro sul do país (18).

Segundo Akamine et al. (2), a propagação do maracujazeiro pode ser feita de forma sexual (sementes) e assexual (enxertia, estaquia e alporquia), entretanto, a forma mais usual é a sexual (19) embora, o baixo percentual de germinação das sementes dificulte a utilização desta forma de propagação (13). Porém, mesmo nos casos de utilização da enxertia, faz-se necessário o uso de sementes para a produção dos porta-enxerto.

A embebição das sementes caracteriza a primeira fase do processo de germinação, ativando o metabolismo das sementes. O conhecimento da duração do período de embebição é importante para a definição do tempo de imersão das sementes em tratamento. Ferreira (9), estudando a embebição de passifloráceas, observou que a máxima absorção de água em sementes de Passiflora alata foi alcançada após 5 horas de embebição.

$\mathrm{Na}$ maioria das passifloráceas as sementes consideradas fisiológicamente maduras tem demonstrado baixo índice de germinação, sugerindo a existência de dormência devido a um fator ou a combinação de fatores (3). Carvalho e Nakagawa (7) apontam o controle de entrada de água na semente, o controle do desenvolvimento do eixo embrionário e o equilíbrio entre substâncias promotoras e inibidoras, como os principais sistemas de dormência.

A impermeabilidade do tegumento como causa da dormência em passifloráceas foi descrito por Morley-Bunker (15) após ter observado que a germinação de algumas espécies aumentou com a escarificação mecânica, sob temperaturas alternadas. Entretanto, estudo recente demonstrou que sementes de cinco espécies de passifloráceas, incluindo o $P$. alata, não apresentam impermeabilidade à água (9).

Outro aspecto importante da germinação que deve ser salientado é o estudo dos reguladores vegetais, uma vez que a presença de inibidores pode impedir ou reduzir a germinação (6). Reguladores vegetais como as giberelinas e citocininas, podem promover a germinação, enquanto inibidores como o ácido abscísico podem inibí-la (5). A germinação pode ocorrer na presença de inibidores desde que a concentração destes seja menor que a de promotores. A dormência depende do balanço entre promotores e inibidores podendo ser superada pela aplicação de promotores ou ampliada pela aplicação de inibidores (22).

Estudando métodos para superação da dormência de $P$. alata, Sanchez (20) obteve melhores resultados com a aplicação de $\mathrm{KNO}_{3}$, seguido por ácido giberélico (500 mg. $\left.\mathrm{L}^{-1}\right)$, com germinação de 50 e $30 \%$, respectivamente. No entanto, Morley- Bunker (14) não obteve resultados satisfatórios em ensaio com a utilização de várias concentrações de $\mathrm{GA}_{3}$, embora não tenha descartado a existência de uma relação hormonal na dormência.

Melo et al. citado por Osipi (17), comparando a germinação de passifloráceas sob temperatura constante de $30^{\circ} \mathrm{C}$ constatou diferença significativa entre as espécies, onde $P$. alata não apresentou germinação.

A temperatura influencia a porcentagem, a velocidade e a uniformidade de germinação. A máxima germinação é obtida dentro de limites, que pode ser uma faixa ou uma dada temperatura. Temperaturas alternadas podem favorecer a germinação de algumas espécies; entretanto, as razões deste efeito ainda não estão totalmente elucidados (7).

Dessa forma, esse trabalho objetivou avaliar a germinação de sementes de $P$. alata em resposta à aplicação de fitorreguladores isolados e combinados.

\section{MATERIAL E MÉTODOS}

O experimento foi conduzido no Laboratório de Análise de Sementes do Departamento de Produção Vegetal - Setor Agricultura da Faculdade de Ciências Agronômicas do campus de Botucatu - UNESP, entre os meses de maio e junho/2000. As sementes utilizadas no experimento foram obtidas de frutos comerciais maduros e extraídas pelo método da fricção em areia (12). Em seguida, as sementes foram mantidas sobre peneiras plásticas de malha fina, por um período de quatro dias à sombra, para secagem.

O teor de água das sementes, após a secagem, foi determinado através do método da estufa à $105^{\circ} \mathrm{C} \pm 3^{\circ} \mathrm{C}$, conforme recomendações das Regras para Análise de Sementes (6).

Foram utilizados os fitorreguladores $\mathrm{GA}_{3}$ (ProGibb, produto comercial $10 \%$ de $\mathrm{GA}_{3}$, na forma de pó solúvel), N-fenilmetil-9-Tetra-Hidro-2H-2 piranil $9 \mathrm{H}-6$ amino purina (FTPA), (Accel, produto comercial, contendo $1,3 \%$ de FTPA) e ethephon (Ethrel, produto comercial contendo $240 \mathrm{~g} / \mathrm{l}$ de ethephon). O delineamento experimental utilizado foi inteiramente casualizado, com 14 tratamentos e quatro repetições contendo 50 sementes cada. Os tratamentos corresponderam as concentrações de 75 e 150 mg.L-1 de cada fitorregulador, mais a combinação de fitorreguladores pareada em concentrações idênticas, as sementes embebidas apenas em água destilada e sementes sem tratamento (testemunha).

A aplicação dos fitorreguladores foi realizado mediante imersão das sementes em soluções preparadas com os fitorreguladores por um período de cinco horas, conforme estudos de embebição realizado por Ferreira (9) para sementes dessa espécie. O mesmo ocorreu para as sementes embebidas apenas em água destilada. 
Após os tratamentos, as sementes foram submetidas ao teste de germinação, utilizando-se como substrato rolos de papel, umedecidos na proporção de 2,5 vezes o seu peso seco com água destilada. Durante o período de germinação, os rolos de papel foram mantidos no interior de sacos plásticos em câmara de germinação, na ausência de luz, sob temperatura de $25^{\circ} \mathrm{C}$ por 35 dias e temperatura alternada de $20-30{ }^{\circ} \mathrm{C}$ (16/8 horas respectivamente), por mais 35 dias. A umidade do substrato foi monitorada, periodicamente, adicionando-se água sempre que necessário.

As contagens do teste de germinação foram realizadas a cada três dias a partir da semeadura. Foram observadas a porcentagem de sementes com emissão da radícula $(>1 \mathrm{~mm}$ ), porcentagem de plântulas normais e, ao final do teste foi determinada a porcentagem de sementes duras. Os critérios de normalidade foram baseados nas Regras para Análise de Sementes (6).

O índice de velocidade de germinação (IVG) foi determinado em conjunto com o teste de germinação, avaliando-se diariamente a porcentagem de plântulas normais. O IVG foi determinado pela fórmula: IVG $=N_{1} / D_{1}+N_{2} / D_{2}+\ldots+N_{n} / D_{n}$, onde: IVG $=$ índice de velocidade de germinação; $\mathrm{N}_{1}, \mathrm{~N}_{2}, \mathrm{~N}_{\mathrm{n}}=$ número de plântulas germinadas a 1, 2 e $\mathrm{n}$ dias após a montagem do teste; $D_{1}, D_{2}, D_{n}=$ número de dias após a implantação do teste. $O$ índice de velocidade de emissão da radícula foi determinado pela mesma fórmula levando em consideração apenas o tamanho da radícula, independente da plântula desenvolvida ser normal ou anormal.

As sementes duras foram avaliadas mediante o teste de tetrazólio (21), para determinação da porcentagem de sementes dormentes e mortas. Para tanto, as sementes não germinadas foram cortadas transversalmente e mergulhadas em solução de tetrazólio a $0,1 \%$, durante três horas, na ausência de luz e à temperatura de $35^{\circ} \mathrm{C}$. A leitura foi realizada mediante avaliação da coloração das partes do embrião. Tecidos com coloração vermelha ou rosa foram considerados viáveis e tecidos branco-leitosos ou vermelhointensos, considerados não viáveis.

Os resultados dos parâmetros avaliados foram submetidos à análise de variância, e as médias, não transformadas, comparadas pelo teste de Tukey a $5 \%$ de probabilidade.

\section{RESULTADOS E DISCUSSÃO}

A porcentagem de germinação até os 35 dias após a instalação do experimento, sob temperatura constante de $25^{\circ} \mathrm{C}$, foi nula para todos os tratamentos avaliados, não se observando ao menos protusão da radícula. Segundo Santos et al. (21), sementes de passifloráceas germinam em até trinta dias após a semeadura, entretanto, destacam a influência da temperatura neste processo. Sob condições de temperatura constante de $30{ }^{\circ} \mathrm{C}$, Melo et al. citado por Osipi
(17) constataram ausência de germinação em sementes de Passiflora alata. Maior porcentagem de sementes duras e mortas foram verificadas por Santos et al. (21) em sementes de Passiflora edulis, sob temperatura constante de $25{ }^{\circ} \mathrm{C}$, independente do substrato utilizado.

Para sementes de Passiflora edulis, em substrato de rolo de papel e temperatura constante de $25{ }^{\circ} \mathrm{C}$ ou alternada de $20-30{ }^{\circ} \mathrm{C}$, as Regras para Análise de Sementes (6), recomendam a realização da primeira contagem de sementes germinadas aos sete dias após a semeadura e outra ao final de 28 dias. No entanto Akamine et al. (2) mencionam haver diferenças entre as diferentes espécies de passifloraceas quanto a germinação. Ferreira (9) observou germinação lenta e gradativa em sementes de $P$. alata, sob temperatura alternada de $20-30^{\circ} \mathrm{C}$, quando comparada com outras espécies de passifloraceas, observando entretanto, início da germinação no oitavo dia após a semeadura. Osipi (17) obteve plântulas normais dessa mesma espécie 14 dias após a semeadura sob temperatura alternada de $20-30^{\circ} \mathrm{C}$ e constante de $25^{\circ} \mathrm{C}$.

Considerando os resultados obtidos sob temperaturas alternadas nessa espécie por Ferreira (9) e Osipi (17) e a ausência de germinação observada aos 35 dias após a semeadura sob temperatura constante de $25^{\circ} \mathrm{C}$, essa foi alterada para $20-30{ }^{\circ} \mathrm{C}$ alternada.

No terceiro dia após a alteração da temperatura observou-se início da germinação em todos os tratamentos, verificando-se a influência favorável da temperatura alternada sobre a germinação e velocidade de germinação de sementes dessa espécie (Quadro 1). Efeitos favoráveis da temperatura alternada de $20-30{ }^{\circ} \mathrm{C}$ também foram constatadas por Santos et al. (21) ao estudarem o efeito da temperatura e do substrato na germinação de Passiflora edulis Sims f. flavicarpa Deg.; verificaram que a porcentagem de germinação, em rolo de papel, obtida aos 21 dias foi semelhante a obtida aos 28 dias recomendados pelas Regras de análise de Sementes (6). A alternância de temperatura atua sobre os tegumentos das sementes tornando-os mais permeáveis à água e ao oxigênio, agindo também sobre o equilíbrio entre substâncias promotoras e inibidoras da germinação (8).

Germinação superior a $80 \%$ em sementes de $P$. alata sob temperatura alternada de $20-30^{\circ} \mathrm{C}$, foi verificada por Ferreira (9) no tratamento testemunha ao estudar a embebição e o efeito de fitorreguladores na germinação de sementes dessa espécie. O efeito favorável dessa alternância na superação da dormência das sementes de $P$. alata foi comprovado por Osipi (17), possibilitando maior porcentagem de germinação.

Os valores médios de germinação, Índice de Velocidade de Germinação e emissão de radícula e sementes duras obtidos no término do teste, apresentados no Quadro 1, demonstram que os fitorreguladores, isolados ou em mistura não mostraram efeitos positivos sobre a germinação e índices de velocidade. Contudo, Ferreira (9) avaliando o efeito 
de vários fitorreguladores, isolados e em misturas, na germinação de cinco espécies de passifloraceas, sob temperatura alternada, observou que o uso desses favoreceu a germinação de sementes de $P$. alata, $P$. edulis Sims. f. flavicarpa e $P$. giberti. Para $P$. alata.
Todos os tratamentos demostraram baixa germinação, sendo que as maiores porcentagens de germinação $(49,5 \%)$, Índice de velocidade de germinação (0.47) e Índice de velocidade de emissão da radícula (0.55) foram obtidas no tratamento testemunha.

QUADRO 1 - Valores médios de germinação, Índice de Velocidade de Germinação (IVG), índice de velocidade de emissão de radicula (IVER) e sementes duras obtidas a no teste de germinação de sementes de maracujá ( $P$. alata Curtis). UNESP-Botucatu, maio-junho de 2000.

\begin{tabular}{|c|c|c|c|c|}
\hline TRATAMENTO & GERMINAÇÃO (\%) & IVG & IVER & DURAS (\%) \\
\hline Testemunha & 49.5 a & $0.47 \mathrm{a}$ & $0.55 \mathrm{a}$ & $46.3 \mathrm{e}$ \\
\hline Água destilada & $41.9 \mathrm{abc}$ & $0.39 \mathrm{abc}$ & $0.46 \mathrm{abc}$ & 57.5 abcde \\
\hline $\mathrm{GA}_{3} 75$ & $42.0 \mathrm{abc}$ & $0.39 \mathrm{abc}$ & $0.45 \mathrm{abc}$ & 55.5 cde \\
\hline $\mathrm{GA}_{3} 150$ & $38.4 \mathrm{abcd}$ & $0.40 \mathrm{ab}$ & $0.45 \mathrm{abc}$ & 61.5 abcde \\
\hline FTPA 75 & $35.0 \mathrm{abcd}$ & $0.32 \mathrm{abcd}$ & $0.35 \mathrm{abc}$ & 65.0 abcde \\
\hline FTPA 150 & $31.4 \mathrm{abcd}$ & $0.29 \mathrm{abcd}$ & $0.34 \mathrm{abc}$ & $67.5 \mathrm{abcd}$ \\
\hline ET 75 & $42.4 \mathrm{abc}$ & $0.38 \mathrm{abcd}$ & $0.46 \mathrm{abc}$ & $52.5 \mathrm{de}$ \\
\hline ET 150 & $46.0 \mathrm{ab}$ & $0.43 a b$ & $0.50 \mathrm{ab}$ & $51.5 \mathrm{de}$ \\
\hline $\mathrm{GA}_{3}+\mathrm{FTPA} 75$ & $29.8 \mathrm{bcd}$ & $0.27 \mathrm{abcd}$ & $0.33 a b c$ & $72.1 \mathrm{abc}$ \\
\hline $\mathrm{GA}_{3}+\mathrm{FTPA} 150$ & $21.4 \mathrm{~d}$ & $0.20 \mathrm{~d}$ & $0.28 \mathrm{bc}$ & $76.0 \mathrm{a}$ \\
\hline $\mathrm{GA}_{3}+\mathrm{ET} 75$ & $41.4 \mathrm{abc}$ & $0.27 \mathrm{abcd}$ & $0.47 \mathrm{abc}$ & 57.0 bcde \\
\hline $\mathrm{GA}_{3}+\mathrm{ET} 150$ & $21.4 \mathrm{~d}$ & $0.36 \mathrm{abcd}$ & $0.44 \mathrm{abc}$ & 60.4 abcde \\
\hline FTPA + ET 75 & $23.0 \mathrm{~d}$ & $0.21 \mathrm{~cd}$ & $0.25 \mathrm{c}$ & $75.5 \mathrm{ab}$ \\
\hline FTPA + ET 150 & $26.8 \mathrm{~cd}$ & $0.24 \mathrm{bcd}$ & $0.28 \mathrm{bc}$ & $69.0 \mathrm{abcd}$ \\
\hline $\mathrm{CV}(\%)$ & 12.3 & 11.9 & 11.7 & 8.7 \\
\hline
\end{tabular}

- Médias seguidas por mesma letra na coluna não diferem entre si pelo teste de Tukey a $5 \%$ de probabilidade.

Onde: $\mathrm{GA}_{3}=$ Giberelina (Pro-Gibb) ; FTPA= Citocinina(Accel) ; ET= Etileno (Ethrel).

As combinações de fitorreguladores, à exceção de $\mathrm{GA}_{3}+\mathrm{ET}$ na concetração de $75 \mathrm{mg} \cdot \mathrm{L}^{-1}$, promoveram inibição na germinação, independente da concentração avaliada. Dessas, a maioria são combinações contendo citocininas, não se verificando portanto, efeito sinergístico da citocinina, aplicada em conjunto com giberelina, como relatado por Anderson (4). As citocininas não favorecem a germinação da maioria das espécies (5), e pelos resultados ora obtidos pode-se colocar o $P$. alata nessa mesma condição.

Os índices de velocidade de germinação e de emisão emissão da radícula foram afetados negativamente pelas combinações giberelina com citocinina, na concentração de $150 \mathrm{mg} \cdot \mathrm{L}^{-1}$ e de etileno com citocinina, em ambas as concentrações. O etileno pode inibir ou promover a germinação (1), entretanto, em sementes de $P$. alata, atuou inibindo. Mesmo em combinações com citocinina e giberelina, não promoveu bons resultados (9).

As porcentagens de sementes duras obtidas ao término do teste foram inversamente proporcionais as de germinadas, ou seja, os tratamentos com menor porcentagem de plântulas normais resultaram em maior porcentagem de sementes duras. As menores porcentagens de sementes duras foram obser- vadas nos tratamentos testemunha e etileno isolado para ambas as concentrações. As maiores foram obtidas nos tratamentos contendo citocinina isolada, na concentração de $150 \mathrm{mg} \cdot \mathrm{L}^{-1}$, e combinada com etileno e giberelina em ambas as concentrações, contrariando os resultados obtidos por Ferreira (9) onde os tratamentos contendo citocinina e giberelinas promoveram melhores resultados em relação ao processo germinativo de sementes dessa espécie. Constatase, desse modo, que os fitoreguladores não beneficiaram o processo de germinação mesmo que pela formação de plântulas anormais.

Os valores de sementes viáveis e inviáveis obtidas no teste de tetrazólio, são apresentados no Quadro 2, onde verificou-se maiores porcentagens de sementes viáveis nos tratamentos contendo giberelina e etileno, na concentração de $75 \mathrm{mg} \cdot \mathrm{L}^{-1}$, combinação desses para essa mesma dosagem e para todos contendo citocinina, isolada e em mistura.

Verificou-se que os tratamentos com menor porcentagem de germinação, principalmente os contendo citocinina, resultaram em maior porcentagem de sementes duras. No entanto, pelo teste de tetrazólio, os tratamentos com maiores porcentagens de sementes duras foram 
os que apresentaram maiores valores de sementes viáveis. Dessa forma, a baixa germinação nesses tratamentos desses não pode ser atribuída a viabilidade das sementes, podendo-se in- ferir que a germinação não ocorreu devido a fatores fisiológicos da semente, uma vez que todos os tratamentos foram submetidos as mesmas condições externas.

QUADRO 2 - Valores médios da porcentagem de sementes viáveis e inviáveis, obtidas no teste de tetrazólio, com sementes duras de maracujá ( $P$. alata Curtis). UNESP-Botucatu, maio-junho de 2000.

\begin{tabular}{|c|c|c|}
\hline TRATAMENTO & VIÁVEIS & INVIÁVEIS \\
\hline Testemunha & 52.2 bc & $47.8 \mathrm{ab}$ \\
\hline Água destilada & $54.3 \mathrm{bc}$ & $45.7 \mathrm{ab}$ \\
\hline $\mathrm{GA}_{3} 75$ & $63.5 \mathrm{ab}$ & $36.5 \mathrm{abc}$ \\
\hline $\mathrm{GA}_{3} 150$ & $52.2 \mathrm{bc}$ & $47.8 \mathrm{ab}$ \\
\hline FTPA 75 & $64.6 a b$ & $35.4 \mathrm{bc}$ \\
\hline FTPA 150 & $76.0 \mathrm{a}$ & $24.0 \mathrm{c}$ \\
\hline ET 75 & $59.3 \mathrm{abc}$ & $40.7 \mathrm{ab}$ \\
\hline ET 150 & $58.6 \mathrm{bc}$ & $41.4 \mathrm{ab}$ \\
\hline $\mathrm{GA}_{3}+\mathrm{FTPA} 75$ & $65.0 \mathrm{ab}$ & $34.0 \mathrm{bc}$ \\
\hline $\mathrm{GA}_{3}+\mathrm{FTPA} 150$ & $59.5 \mathrm{abc}$ & $40.5 \mathrm{ab}$ \\
\hline $\mathrm{GA}_{3}+\mathrm{ET} 75$ & $59.3 \mathrm{abc}$ & $40.7 \mathrm{ab}$ \\
\hline $\mathrm{GA}_{3}+\mathrm{ET} 150$ & $45.0 \mathrm{c}$ & $55.0 \mathrm{a}$ \\
\hline FTPA + ET 75 & $66.8 \mathrm{ab}$ & $33.2 \mathrm{bc}$ \\
\hline FTPA + ET 150 & $66.2 \mathrm{ab}$ & $33.8 \mathrm{bc}$ \\
\hline CV (\%) & 8.1 & 10.4 \\
\hline
\end{tabular}

- Médias seguidas por mesma letra na coluna não diferem entre si pelo teste de Tukey a $5 \%$ de probabilidade.

Onde: $\mathrm{GA}_{3}=$ Giberelina (Pro-Gibb) ; FTPA= Citocinina(Accel) ; ET= Etileno (Ethrel).

A alta porcentagem de sementes inviáveis para todos os tratamentos, possivelmente ocorreu devido ao longo período de condução do teste, durante o qual, as sementes permaneceram sob condições de alta temperatura e umidade, e possivelmente sob condições externas inadequadas no primeiro período de condução. Essas condições desfavoráveis podem ter induzido ou acelerado o processo de deterioração das sementes, resultando na morte das mesmas.

Os baixos valores de germinação, bem como os maiores índices de sementes viáveis nos tratamentos com fitorreguladores, possivelmente ocorreram em função do desequilíbrio hormonal, promovido pela aplicação dos mesmos em dosagens inadequadas ou desbalanceadas no caso das misturas, pois para que seja verificado efeito na germinação, há necessidade da aplicação do fitorregulador específico e na dosagem adequada à espécie. $O$ balanço hormonal pare- ce ser favorecido naturalmente pela alternância de temperatura, como pode ser observado no tratamento testemunha. A aplicação de fitorreguladores pode determinar ou favorecer o processo germinativo de sementes dessa espécie (4), (5), (9) e (20), necessitando, entretanto, de maiores estudos para determinação de concentrações e combinações diferentes daquelas analisadas neste trabalho.

\section{CONCLUSÕES}

Os fitorreguladores $\mathrm{GA}_{3}$, N-fenilmetil-9-Tetra-Hidro$2 \mathrm{H}-2$ piranil $9 \mathrm{H}-6$ amino purina e ethephon, isolados ou em misturas, nas dosagens de 75 e $150 \mathrm{mg} \cdot \mathrm{L}^{-1}$ não favoreceram o processo germinativo de sementes de $P$. alata. 


\section{REFERÊNCIAS BIBLIOGRÁFICAS}

1. ABELES, F.B.; MORGAN, P.W.; SALTVEIT JÚNIOR, M.E. Ethylene in plant biology. 2. ed. California: Academic Press, 1992. 414p.

2. AKAMINE, E.K.; BEAUMONT, J.H.; BOWERS, F.A.I.; HAMILTON, R.A.; NISHIDA, T.; SHAN, T.N. Passion fruit culture in hawaii. Hawaii, University of Hawaii, 1972. 35p. (Extension Circular, 345).

3. ALMEIDA, A.M.; NAKAGAWA, J.; ALMEIDA, R.M. Maturação de sementes de maracujá amarelo. Experimento I. In: CONGRESSO BRASILEIRO DE FRUTICULTURA, 9, 1987, Campinas. Anais... Campinas: sociedade Brasileira de Fruticultura, 1988, p. 625-30.

4. ANDERSON, W.P. Weed science. 3.ed. St. Paul: Nest Publishing, 1983. 655p.

5. BEWLEY, J.D. Dormancy breaking by hormones and other chemicals action at the molecular level. In: RUBENSTEIN, J.; PHILLIPS, R.L.; GREEN, C.E.; GENGENBACH, B.G. The plant seed development, preservation and germination. New York: Academic Press, 1978. p. 219-40.

6. BRASIL, Regras para Análise de Sementes. Brasília, MARA. Departamento Nacional Def. Veg., 1992. 365p.

7. CARVALHO, N.M. \& NAKAGAWA, J. Sementes: ciência, tecnologia e produção. 3. Ed. Campinas: Fundação Cargill, 1988. 424p.

8. CICERO, S.M. Dormência de sementes. In: SEMANA DE ATUALIZAÇÃO EM PRODUÇÃO DE SEMENTES. Piracicaba: FEALQ, 1986. P. 41-74.

9. FERREIRA, G. Estudo da embebição e do efeito de fitorreguladores na germinação de sementes de passifloraceas. Botucatu, 1998. (Tese (Doutorado em Horticultura) - Faculdade de Ciências Agronômicas/UNESP).

10. HOEHNE, F.C. Frutos indígenas. São Paulo: Instituto de botânica, 1946. p.62-5.

11. LEITÃO FILHO, H.F. \& ARANHA, C. Botânica do maracujazeiro. In SIMPÓSIO DA CULTURA DO MARACUJÁ, 1, 1974. $P$ 11-3.

12. MATTOS, V.P.; ADOLFO-FILHO, J.; GONÇALVES, E.P.; SILVA, L.M.M. Germinação de sementes de maracujá (Passiflora edulis Sims - passifloraceae). Informativo ABRATES, Curitiba, v. 9, 1999, p. 200.

13. MELETTI, L.M.M. Situação regional da cultura do maracujá - Sudoeste - Estado de São Paulo. In: REUNIÃO TÉCNICA DE PESQUISA EM MARACUJAZEIRO. 1999, Londrina, p. 15-19.

14. MORLEY-BUNKER, M.J.S. Report on: Some aspects of seed dormency with reference to Passiflora pps. and other tropical and subtropical crops. Londron. Applied. Plant Science. 1974. $43 p$

15. MORLEY-BUNKER, M.J.S. Seed coat dormancy in Passiflora species. Anuu. J. Royal New Zeal. Inst. Hort., n.8, p.72-74, 1980.

16. MOYER, B.S.; ANDERSON, D.B.; BOHNING, R.H. Introdução a fisiologia vegetal. Lisboa: Fundação Calouste Gulben kian, 1970.564p.

17. OSIPI, E.AF. Efeito da temperatura, da maturação do fruto e do armazenamento na qualidade fisiológica de semente de maracujá doce (Passiflora alata Dryander). Botucatu, 2000. 98 p. Tese de Doutorado.

18. PIZAJUNIOR, C.T. Cultura do maracujá. São Paulo: Secretaria da Agricultura, 1966. 102p. (Boletim Técnico 5).

19. RUGGIERO, C.; SÃO JOSÉ, A.R.; VOLPE, C.A.; OLIVEIRA, J.C.; DURIGAN, J.C.; BAUNGARTNER, J.G.; SILVA, J.R.; NAKAMURA, K.; FERREIRA, M.E.; KAVATI, R.; PERREIRA, V.P. Maracujá para exportação: aspectos técnicos da produção. Publ. Téc. FRUPEX, 19, 1996, 64p.

20. SANCHEZ, S.V. Influência de tipos de dosagens e armazenamento sobre a germinação de sementes e estudo sobre a quebra de dormência de maracujá doce (Passiflora alata Ait). Jaboticabal: Faculdade de Ciências Agrárias e Veterinátias, Universidade Estadual Paulista, 1980, 21p. Monografia.

21. SANTO, M.C.; SOUSA, G.R.L.; SILVA, J.R.; SANTOS, V.L.M. Efeito da temperatura e do substrato na germinação de sementes de maracujá (Passiflora edulis Sims flavicarpa Deg.). Revista Brasileira de Sementes, v.21, n.1, p.1-6, 1999.

22. WEAVER, R. J. Reguladores del crecimiento de las plantas en la agricultura. 5ed. Mexico: Trillas, 1987. 622p.

Recebido em 16/08/2001 Aceito em 27/11/2003 